\title{
Aparelho Herbst: Protocolos de tratamento precoce e tardio
}

\author{
Omar Gabriel da Silva Filho*, Carlos Alberto Aiello*, Marcelo Veloso Fontes**
}

\begin{abstract}
Resumo
Até que ponto o crescimento mandibular pode ser realmente influenciado pelos aparelhos ortopédicos de reposicionamento anterior, ainda permanece indecifrável. Mas a lógica leva a crer que se existe alguma chance de potencializar o deslocamento anterior da mandibula, ela será mais certa quando se utiliza aparelhos de avanço contínuo. O presente artigo discorre sobre os protocolos de tratamento precoce e tardio para a correção da deficiência mandibular com o aparelho Herbst.
\end{abstract}

Palavras-chave: Aparelho Herbst. Má oclusão de Angle Classe II. Mandíbula.

\section{ANCORAGEM NA DENTADURA PERMANENTE}

O aparelho Herbst consiste num aparelho intrabucal de ancoragem intermaxilar recíproca. Isso implica que a ação do aparelho em avançar a mandíbula provoca uma reação igual e contrária no arco dentário superior. Assim, a instalação do mecanismo Herbst induz uma força superior e posterior nos dentes superiores (reação) e uma força inferior e anterior nos dentes inferiores (ação). A utilização de uma ancoragem pesada (Fig. 1,2,3) tem pretensões de transformar a ação do mecanismo telescópico em resposta ortopédica (remodelação da ATM e aumento no comprimento mandibular) e neutralizar a força de reação. Neste contexto, o planejamento da ancoragem retoma o propósito de minimizar o efeito ortodôntico em benefício do ganho ortopédico quando da adaptação do mecanismo telescópico bilateral responsável pelo avanço mandibular contínuo.
O que fica claro na literatura é que o aparelho Herbst, depois da sua reintrodução e crescente popularidade na Ortodontia, ganhou diferentes versões. A ancoragem original prevê uma estrutura metálica fixa em ambos os arcos dentários. Uma das possibilidades de ancoragem metálica fixa é o apoio no maior número de dentes posteriores mediante o emprego de uma armação metálica fundida ou sua estrutura mais próxima, que corresponde à armação metálica soldada usando bandas como elemento de união intra-arcos $15,27,28,29,31,34,35$. Tendo como um dos motivos a fragilidade estrutural nos locais de solda, pontos de constante quebra, a estrutura metálica soldada também tem sido substituída pelo esplinte de acrílico cobrindo toda a extensão dos arcos dentários. O esplinte pode ser colado somente no arco dentário inferior ${ }^{12}$ ou em ambos os arcos dentários ${ }^{11,13,14}$, e até mesmo ser removível inferior ${ }^{44}$, ou removível em ambos os arcos dentários ${ }^{2,22,41}$. As ancoragens alternativas

\footnotetext{
* Ortodontistas do Hospital de Reabilitação de Anomalias Craniofaciais, Universidade de São Paulo (HRAC/USP), Bauru-SP.

** Aluno do Curso de Especialização em Ortodontia da Sociedade de Promoção Social do Fissurado Lábio-Palatal (PRO-

FIS), Bauru-SP.
} 

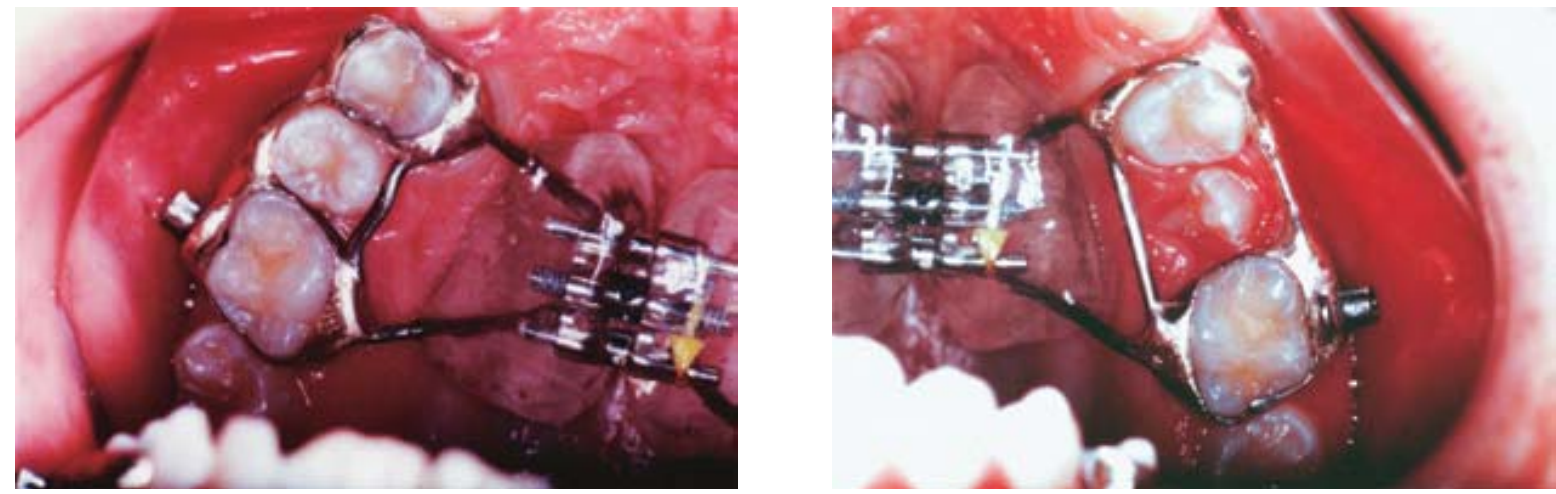

FIGURA 1 - Aparelho expansor fixo tipo Haas modificado usado como ancoragem superior para receber o tubo telescópico do aparelho Herbst. Protocolo de tratamento tardio (dentadura permanente).
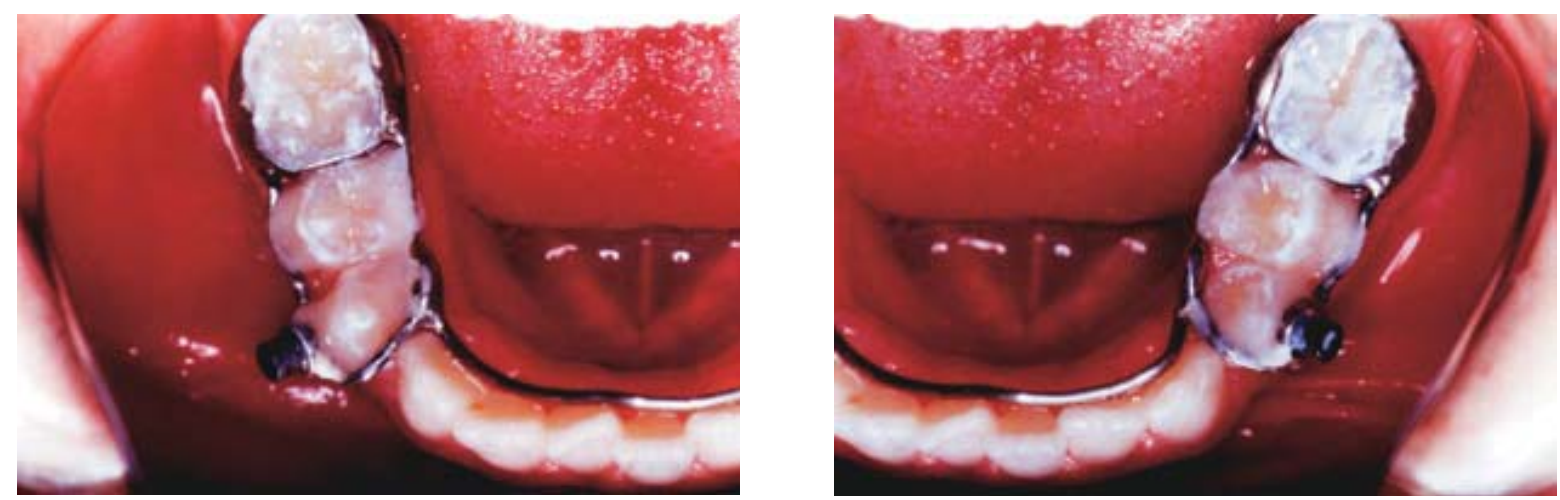

FIGURA 2 - Arco lingual de Nance modificado usado como ancoragem inferior para receber o pistão ou êmbolo do aparelho Herbst. Protocolo de tratamento tardio (dentadura permanente).
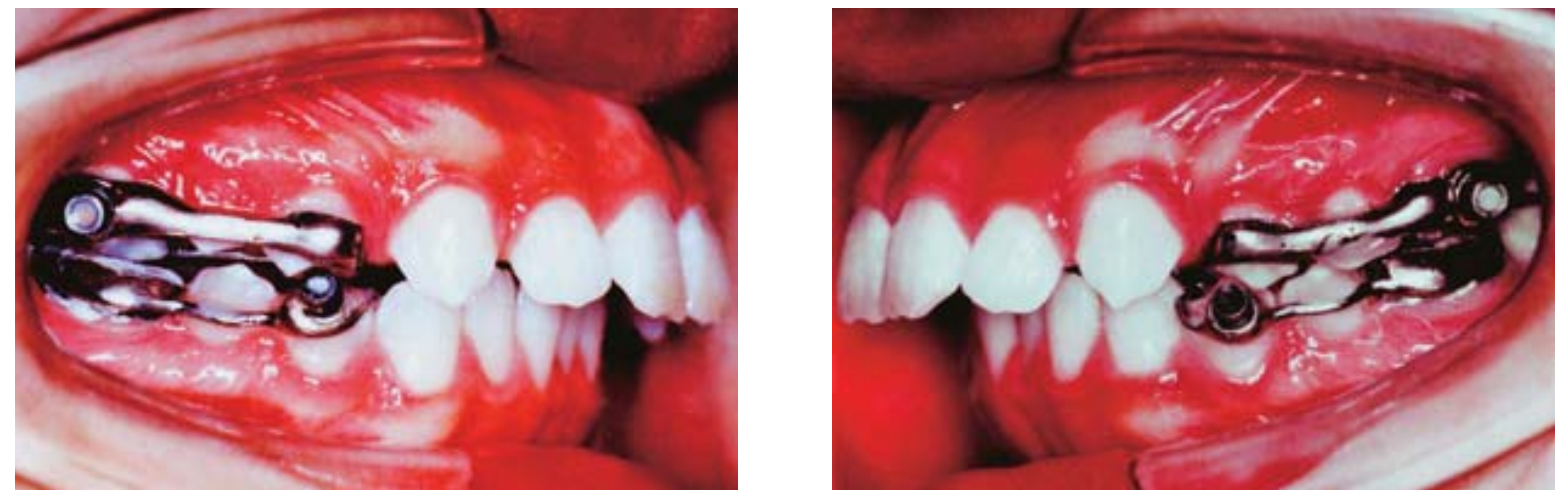

FIGURA 3 - Ancoragens superior e inferior adaptadas e prontas para receberem o mecanismo telescópico de avanço mandibular contínuo. Protocolo de tratamento tardio (dentadura permanente).

para adaptação do mecanismo telescópico ainda contam com cantilever no arco dentário inferior ${ }^{39}$ e as coroas de aço substituindo as bandas ${ }^{8,15,16}$. Há ainda a possibilidade da adaptação do meca- nismo telescópico diretamente no aparelho fixo total superior e inferior ${ }^{4,6,9}$.

A ancoragem superior adotada no presente artigo é fixa e dento-muco-suportada, inde- 
pendentemente do protocolo de tratamento, se instalado na dentadura mista ou na dentadura permanente. $\mathrm{O}$ aparelho baseia-se numa adaptação do aparelho expansor fixo tipo Haas (Fig. 1), usado previamente à instalação do mecanismo telescópico, e com familiaridade pelos autores, para a descompensação transversal da maxila. O apoio mucoso de resina acrílica delineia a abóbada palatina enquanto que a barra de conexão contorna o arco dentário superior em sua maior extensão, ou pelo menos até o seu limite palatino posterior. Depois de instalado o aparelho de ancoragem superior, o parafuso expansor é acionado até a descompensação transversal da maxila, para a correção da deficiência transversal presente com freqüência na má oclusão Classe II, divisão 1 .

A ancoragem inferior, puramente dentária e metálica, tenta recrutar o maior número de dentes possível. Os dentes de ancoragem são unidos por um arco lingual de Nance modificado pela extensão vestibular, que parte do primeiro molar, em direção anterior, para receber o dispositivo que fixa o pistão ou êmbolo do mecanismo telescópico e é interrompida na região de canino, quando é soldada no arco lingual (Fig. 2).

\section{PONDERAÇÕES SOBRE A ÉPOCA DE TRATAR}

Toda mecanoterapia vislumbra um objetivo definido e baseia-se numa estratégia de ação coerentemente planejada levando em consideração características como: morfologia da má oclusão, gravidade do problema, estágio do desenvolvimento oclusal, idade e cooperação do paciente, formação profissional e, finalmente, a própria expectativa do paciente e familiares no tocante aos resultados do tratamento. Isso se aplica também para a má oclusão Classe II, cujo universo terapêutico abrange uma infinidade de aparelhos, bem como épocas diferentes de intervenção, não raro desafiando a concepção morfogenética ao se recorrer aos aparelhos de efeito ortopédico sobre o crescimento mandibular, uma vez que cerca de
70\% das más oclusões Classe II apresentam deficiência mandibular ${ }^{19}$. De um modo geral pode-se resumir em dois os inúmeros protocolos de tratamento para a má oclusão de Classe II, considerando-se a época de tratamento. $\mathrm{O}$ tratamento precoce, em duas fases, e o tratamento tardio, em uma única fase.

Do ponto de vista prático, o presente artigo considera o tratamento precoce aquele realizado nas fases iniciais da dentadura mista, no primeiro período transitório ou no período inter-transitório, já que a relação custo-benefício não justifica a abordagem terapêutica na dentadura decídua. A literatura tem feito menção ao tratamento no estágio de dentadura decídua ${ }^{40}$, mas nos parece demasiadamente cedo quando se considera o tempo excessivamente longo de contenção obrigatória para se manter alguma estabilidade ao longo do crescimento. O protocolo de tratamento precoce abarca uma fase ortopédica inicial que explora a possibilidade de remodelação esquelética, e uma fase ortodôntica de finalização na dentadura permanente. É necessário sublinhar que essas fases terapêuticas são separadas entre si por um hiato de tempo, onde a contenção do efeito induzido pela fase ortopédica se faz necessária para garantir a permanência da relação sagital alcançada ${ }^{31}$. Quando a fase ortopédica é levada a efeito com o aparelho Herbst, concebido para estimular crescimento mandibular, a contenção dos efeitos suscitados é obtida com aparelhos ortopédicos removíveis como, por exemplo, o aparelho Bionator. Se o tratamento precoce contém a virtude do manejo da discrepância esquelética antes da adolescência, tem também o demérito do tratamento prolongado.

O protocolo de tratamento tardio adia a abordagem terapêutica para o segundo período transitório da dentadura mista, após a irrupção completa dos primeiros pré-molares superiores e inferiores ou até mesmo para a dentadura permanente; porém em fase de crescimento, como ilustrado no 

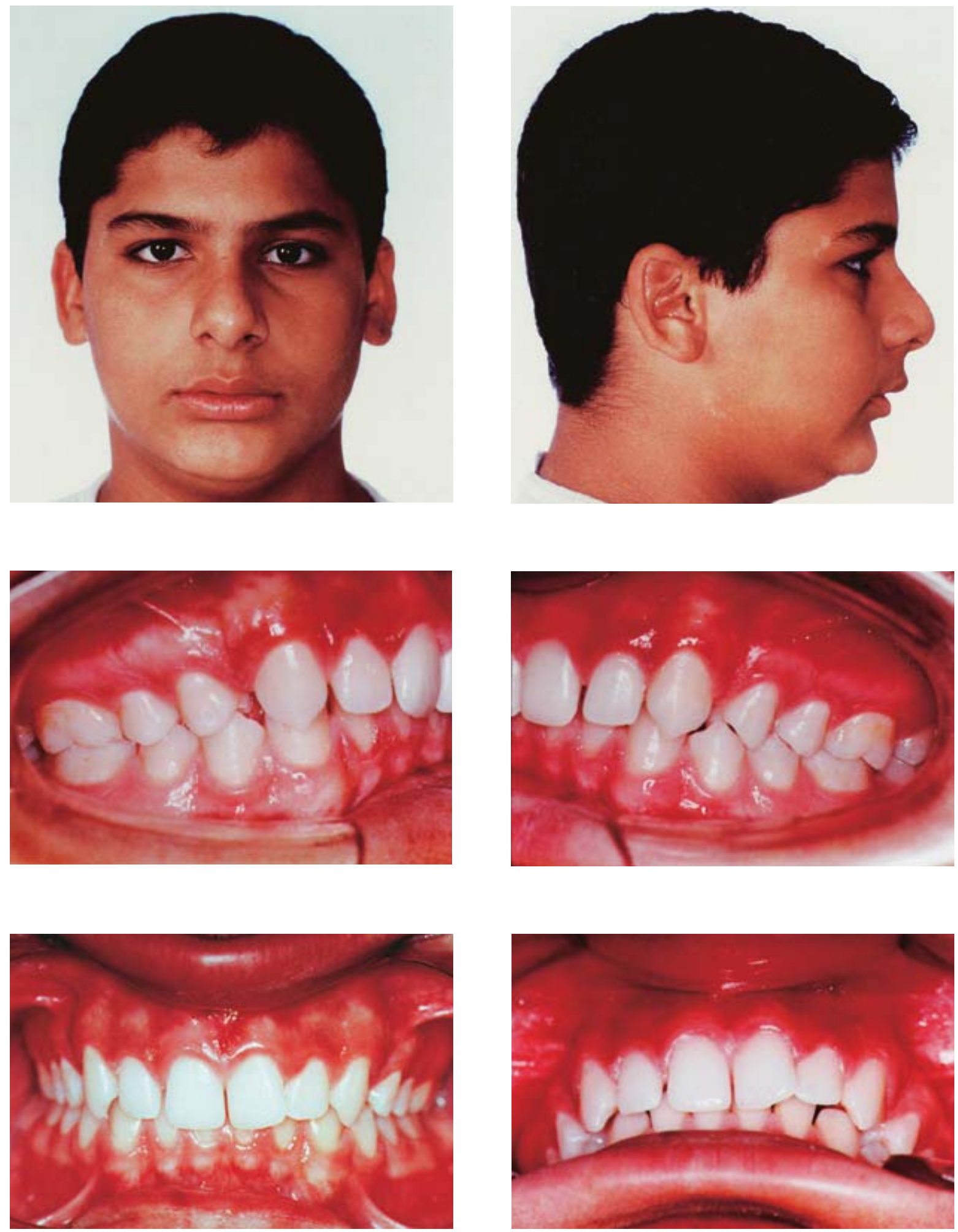

FIGURA 4 - Padrão II, com deficiência mandibular. Má oclusão Classe II, com compensação dentária superior. A má oclusão será tratada obedecendo o protocolo de tratamento tardio: aplicação do aparelho Herbst na dentadura permanente (Figuras 5-9). 

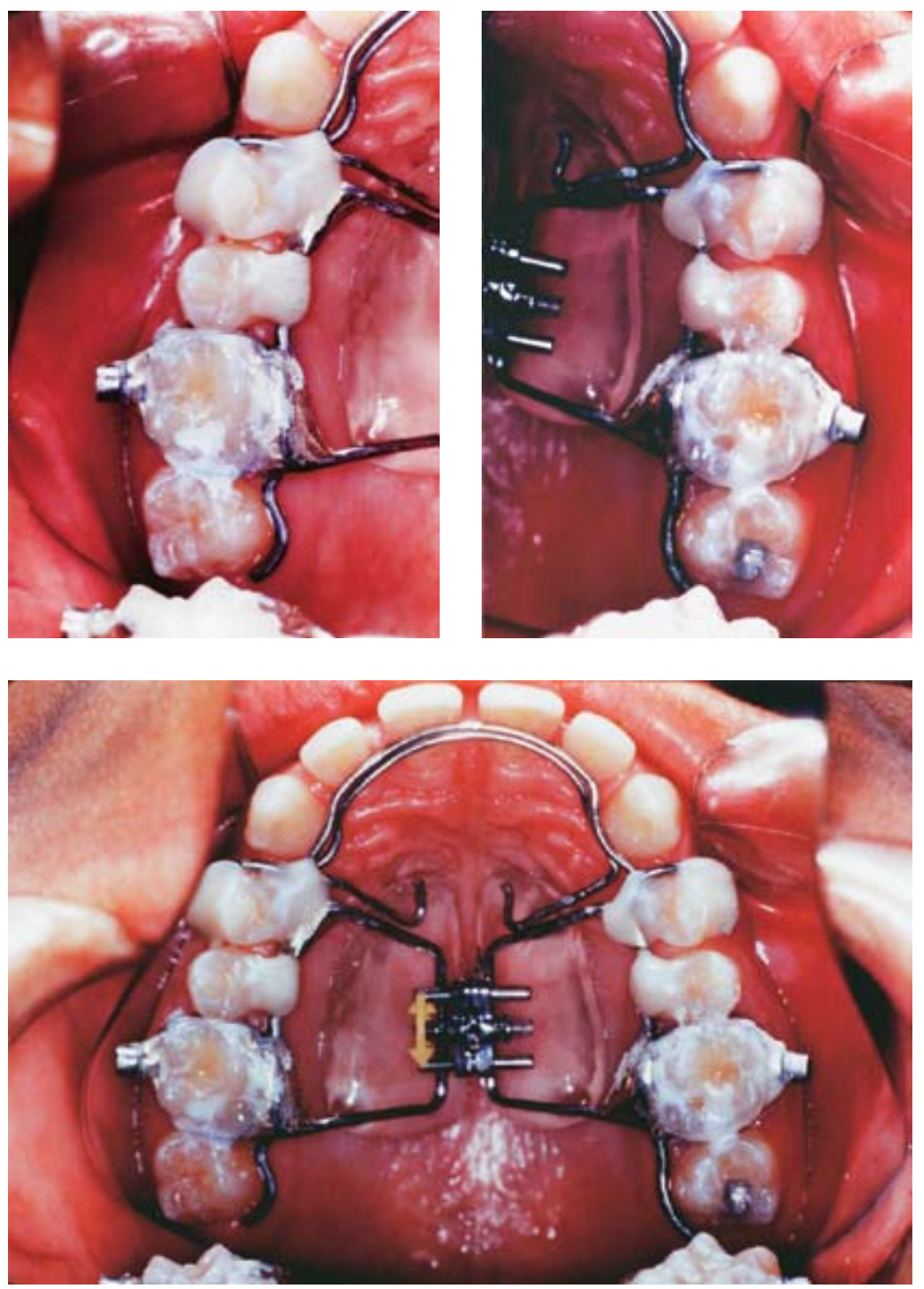

FIGURA 5 - Ancoragem superior (aparelho expansor fixo tipo Haas modificado) com mola de vestibularização dos incisivos superiores. A mecânica visa promover a descompensação dentária superior nos sentidos sagital e transversal, previamente à instalação do mecanismo telescópico.

caso clínico exposto nas figuras 4 a 9. A época da intervenção é controlada pela idade óssea, a qual, com maior precisão que a idade dentária ou cronológica, aproxima o início do tratamento ao pico de crescimento da adolescência ${ }^{33}$. O tratamento tardio pode ser iniciado na maturidade oclusal, porém obrigatoriamente antes da maturidade esquelética. À semelhança do tratamento precoce, o tratamento tardio também inclui as duas fases terapêuticas, ortopédica e ortodôntica; a diferença é que não existe um hiato de tempo entre elas, elas continuam imediatamente.

Os protocolos de tratamento precoce e tardio nos remete a uma reflexão intrigante acerca da eficiência do tratamento ortodôntico, tema que começa a ganhar relevância na Ortodontia contemporânea ${ }^{3,26}$. Aflora um consenso geral de que o melhor tratamento seria aquele que 

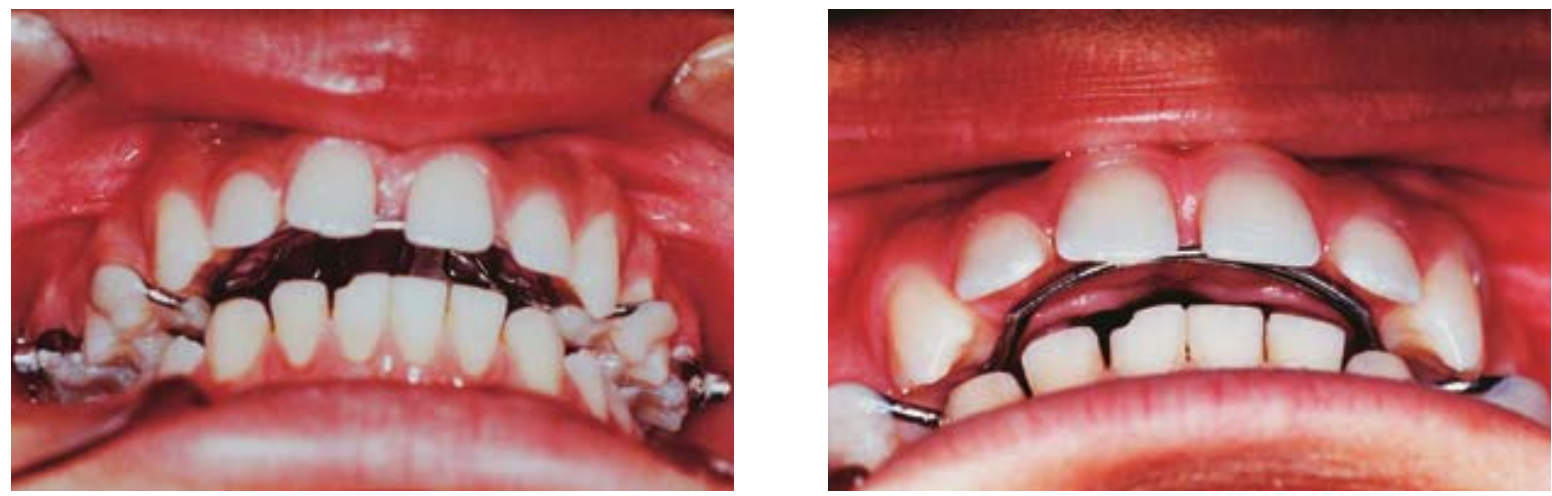

FIGURA 6 - Descompensação superior concluída: nos sentidos sagital e transversa
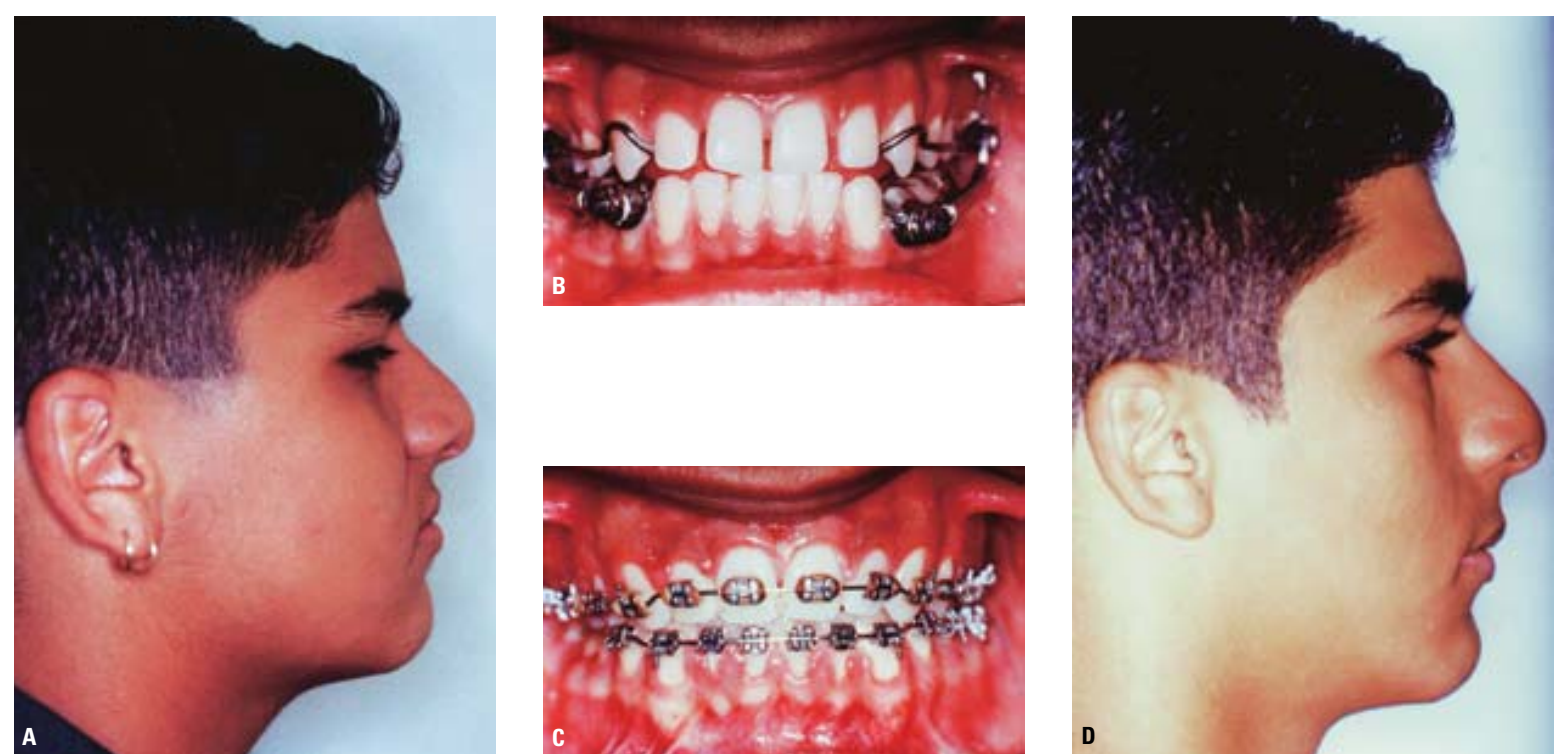

FIGURA 7 - A,B) Avanço mandibular imediato até a sobrecorreção da relação de incisivos. C,D) Finalização ortodôntica pós-tratamento ortopédico, utilizando aparelho ortodôntico fixo total superior e inferior.

envolvesse menor tempo de tratamento com melhor resultado. Nessa perspectiva, há necessidade de determinar a época ideal e o método mais eficiente para o tratamento da má oclusão de Classe II com deficiência mandibular. À luz desse entendimento, a pesquisa acadêmica recente não acata de maneira entusiástica o tratamento precoce e tão pouco o uso de aparelhos removíveis para a correção da má oclusão de Classe II. Principalmente porque enquanto existir crescimento, não é a época em que atua a principal condicionante da magnitude das trans- formações ortopédicas, as quais em média, estão longe de serem espetaculares.

Para ilustrar essa questão, Bremen e Pancherz ${ }^{3}$ deixam claro o escopo de sua pesquisa recémpublicada: avaliar a eficiência do tratamento da má oclusão Classe II, divisão 1, em 204 pacientes. Quanto ao tempo de tratamento ativo, o resultado mostrou-se mais efetivo quando realizado na dentadura permanente, com um período médio de 21 meses de tratamento ativo, em comparação com 57 meses para o início da dentadura mista e 33 meses para o final da dentadura mista ${ }^{3}$. 

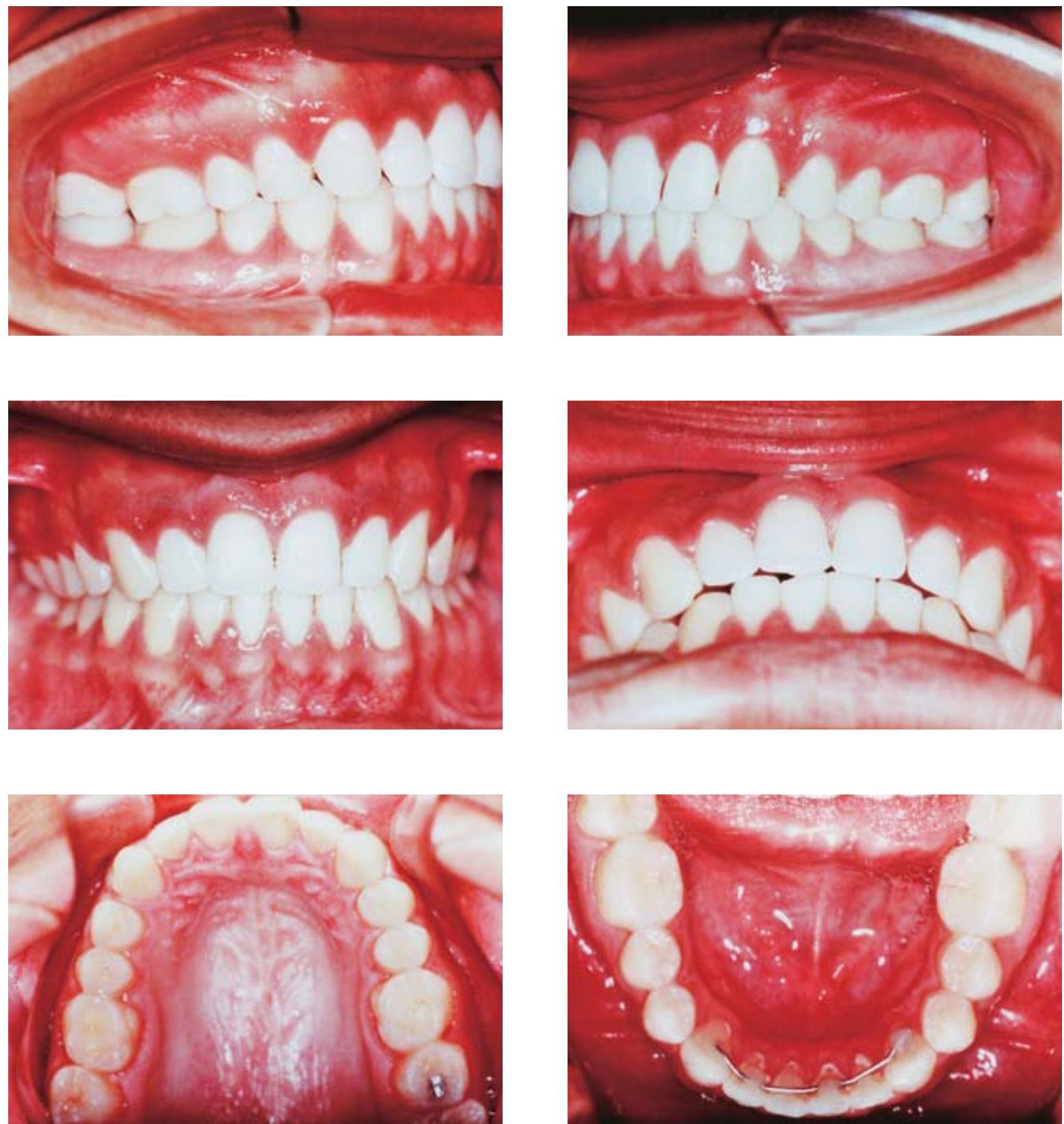

FIGURA 8 - Oclusão normal após o tratamento da má oclusão Classe II com avanço mandibular contínuo, obedecendo ao protocolo de tratamento tardio.

A supremacia do tratamento tardio para Classe II não figura somente neste artigo. Está expressa também em outras pesquisas ${ }^{7,17,25,37}$, principalmente no que se refere à instabilidade dos efeitos ortopédicos suscitados na primeira fase do tratamento $^{37}$. Há relato de que a resposta mandi- bular frente aos aparelhos ortopédicos funcionais removíveis favorece a intervenção mais tardia, sendo que o crescimento mandibular é maior em pacientes com mais de 10,5 anos de idade do que em pacientes com menos idade ${ }^{21}$. A pesquisa supramencionada de Bremen e Pancherz ${ }^{3}$ também 

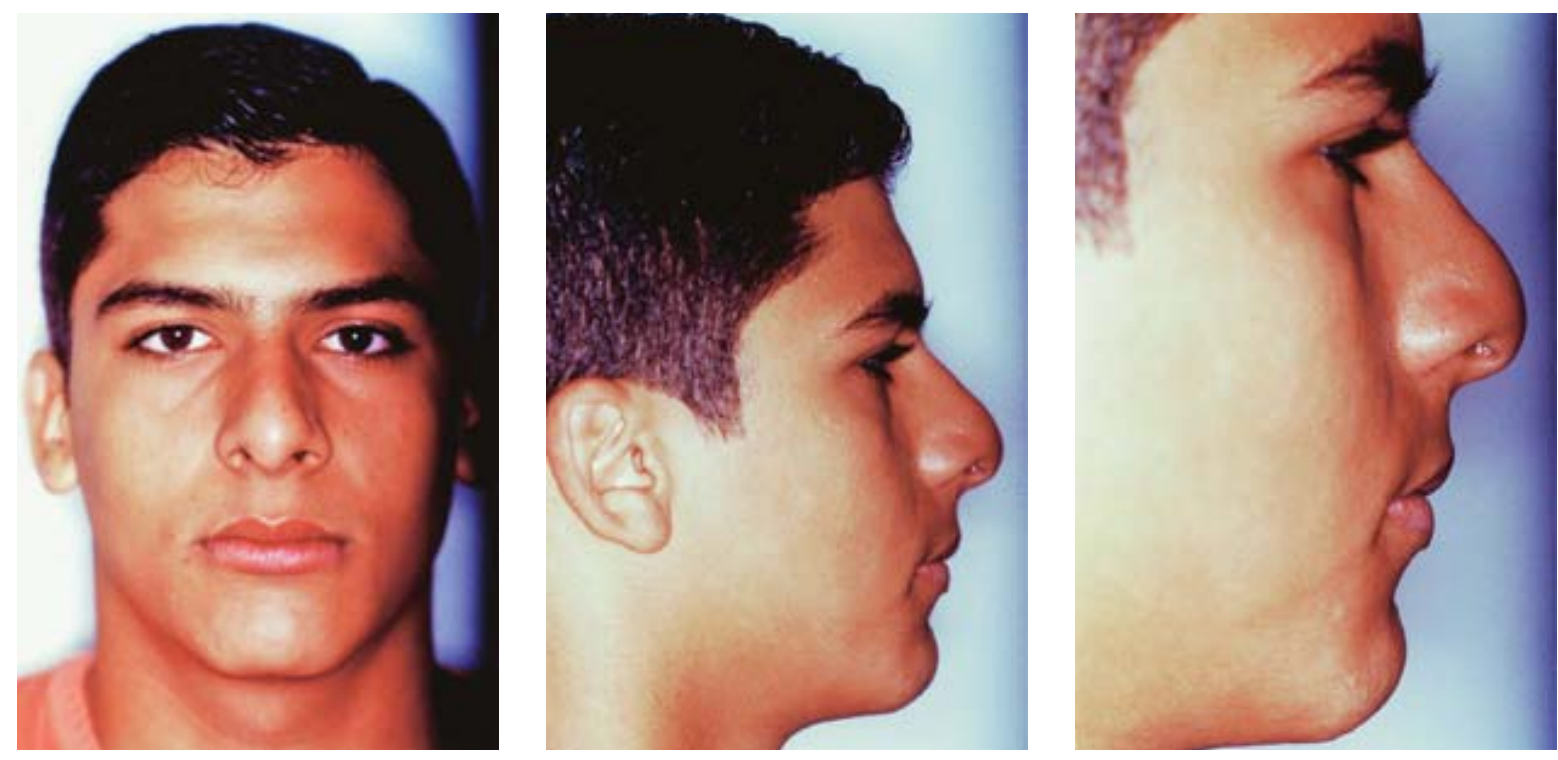

FIGURA 9 - Padrão facial final - obtido com o tratamento ortopédico e ortodôntico.

deixou claro que o tempo de tratamento foi mais curto com aparelhos fixos do que com aparelhos removíveis.

Os testemunhos sobre os benefícios do tratamento da má oclusão Classe II menos precoce e mais tardiamente, não implica, todavia, a condenação do tratamento precoce. O impasse sobre a melhor época de tratamento continua. $\mathrm{O}$ assunto é complexo principalmente pela polêmica presente quando se refere à possibilidade de influência extra-genética sobre o crescimento mandibular ${ }^{5,24}$, a despeito da enorme importância que a prática ortopédica vem ganhando na Ortodontia contemporânea. Além do mais, muitos fatores, nem sempre morfológicos, antecipam o tratamento, como, por exemplo, as implicações psicossociais da má oclusão Classe II, divisão 1 . Outro aspecto de importância primordial está na possibilidade de finalização sem necessidade da segunda etapa do tratamento, ou seja, o tratamento ortodôntico corretivo, como se constata no tratamento precoce das figuras 10 a 22. A nossa experiência revela que em alguns pacientes esta etapa é dispensável. Muito embora a oclusão final encontrada não seja a ideal, ela se enquadra dentro dos conceitos de normalidade. O caso clínico obedecendo o protocolo de tratamento precoce, aqui apresentado, ilustra bem esta situação. Na maturidade oclusal (Fig. 20) pode-se observar irregularidades dentárias cuja sutileza não justificariam o tratamento ortodôntico corretivo com aparelho fixo, quando se considera o custo biológico imposto por este tipo de aparelho à estrutura dental e periodontal. Norteados por estes pontos, os ortodontistas devem elaborar planejamentos individuais, com escolhas conscientes, baseados na relação custo-benefício do tratamento.

O caso clínico apresentado nas figuras 10 a 22 retrata o protocolo de tratamento precoce para a má oclusão Classe II, divisão 1, utilizando-se o aparelho Herbst. A estratégia terapêutica incluiu a mecânica transversal para a correção da discrepância transversal, seguida imediatamente pela mecânica sagital com o aparelho Herbst para correção da relação inter-arcos de Classe II, e, finalmente, a utilização do aparelho removível Bionator (fechado) para a contenção da correção sagital e fechamento da mordida aberta anterior. 

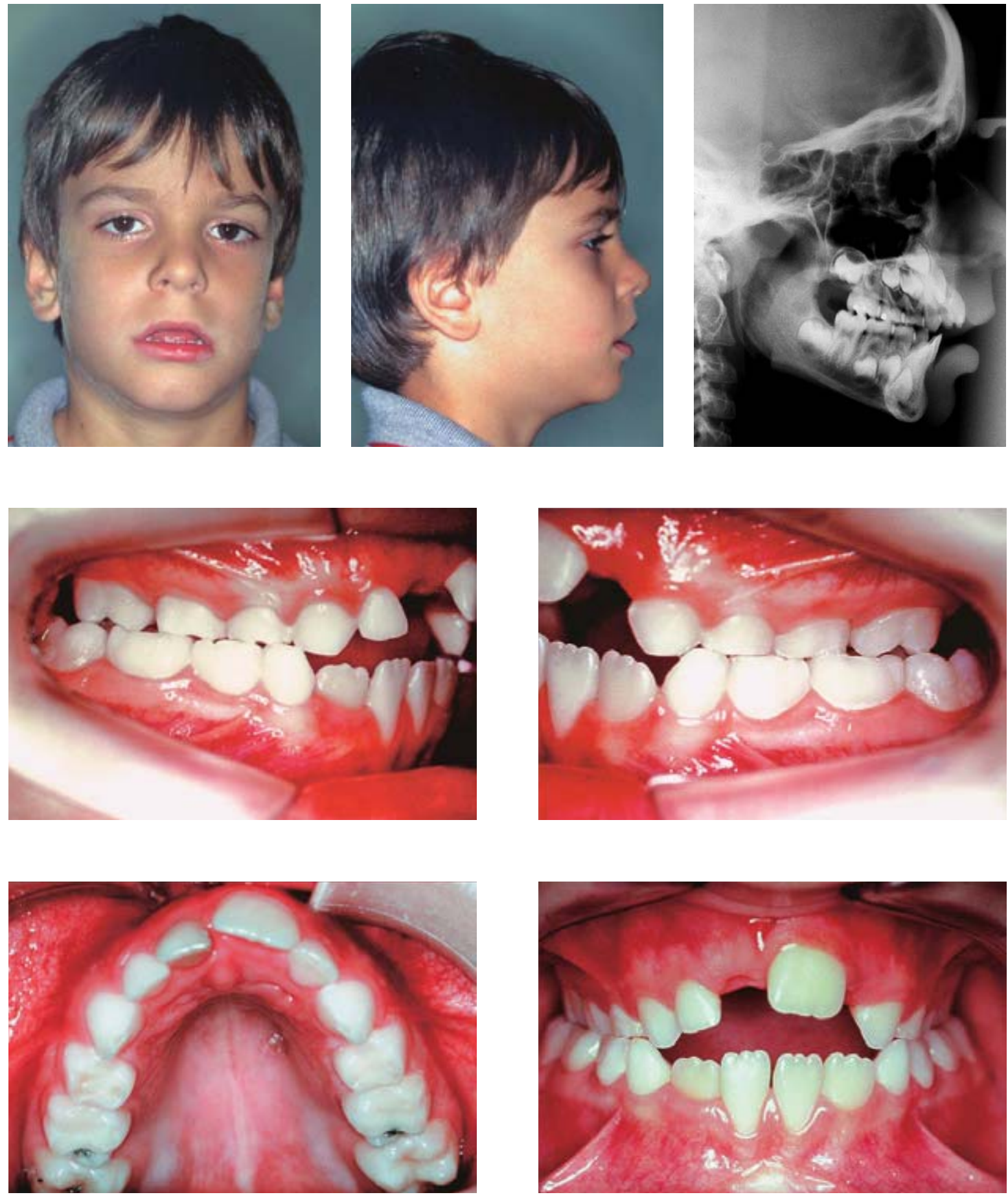

FIGURA 10 - Padrão II, com deficiência mandibular 0 diagnóstico facial, confirmado pela telerradiografia, pede avanço ortopédico da mandíbula como prioridade terapêutica. A análise oclusal revela uma relação dentária de Classe II, acompanhada de atresia do arco dentário superior e mordida aberta anterior. A má oclusão será tratada com o aparelho Herbst obedecendo o protocolo de tratamento precoce (Figuras 11-20). 

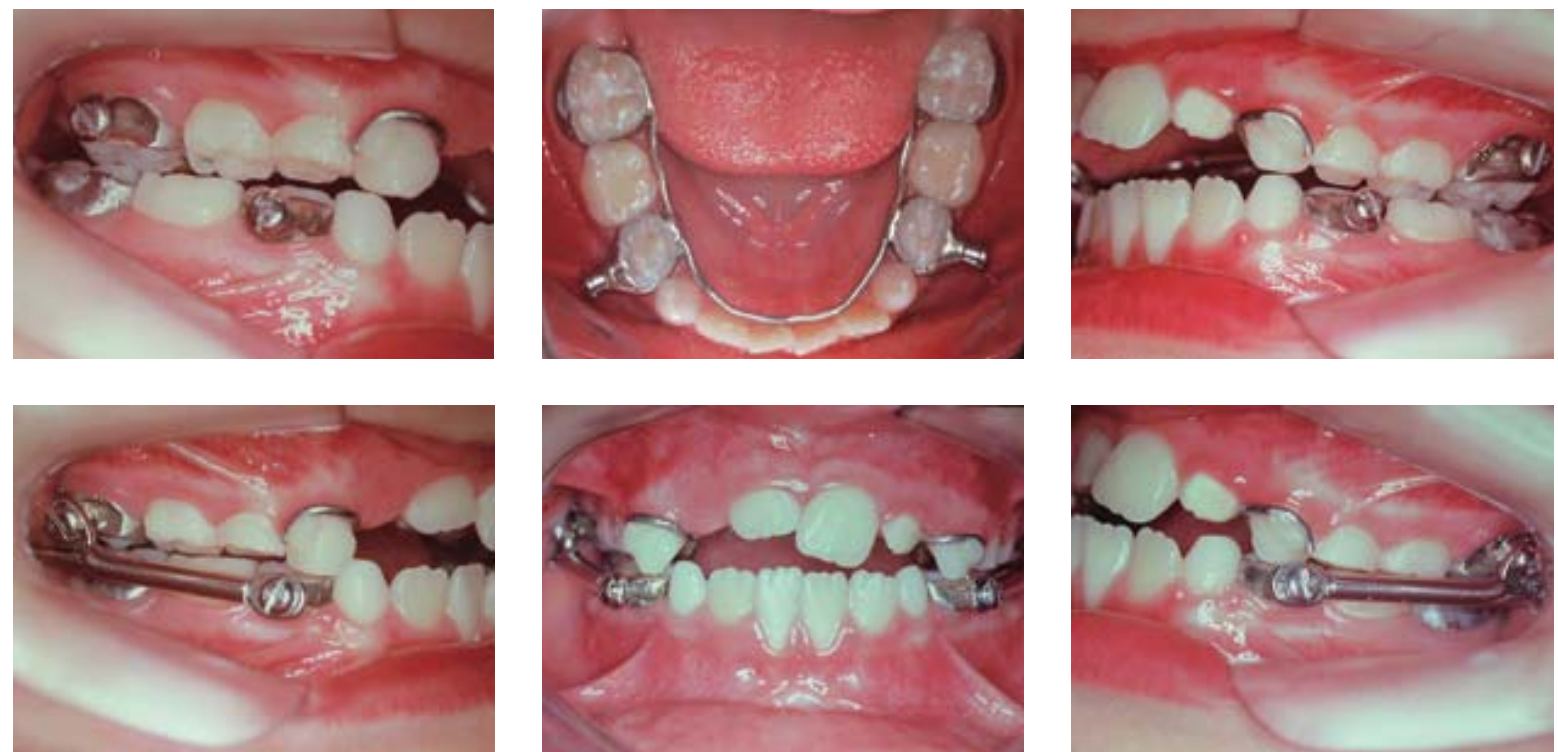

FIGURA 11 - Instalação do mecanismo telescópico para avanço mandibular contínuo (aparelho Herbst) nas ancoragens superior e inferior, após o procedimento de expansão rápida da maxila (descompensação transversal). 0 paciente encontra-se no primeiro período transitório da dentadura mista (protocolo de tratamento precoce).
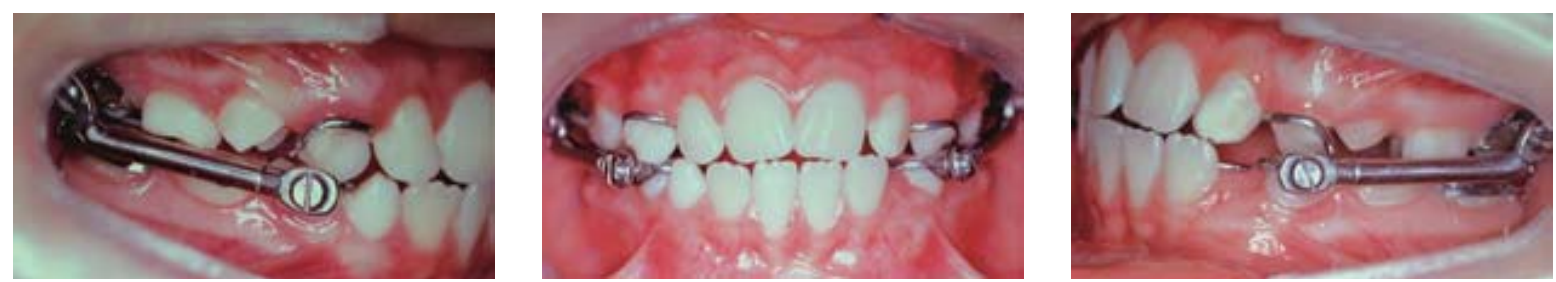

FIGURA 12 - 0 mecanismo telescópico é mantido em posição por um período mínimo de 1 ano. 0 aparelho foi mantido em posição até o início do segundo período transitório da dentadura mista.
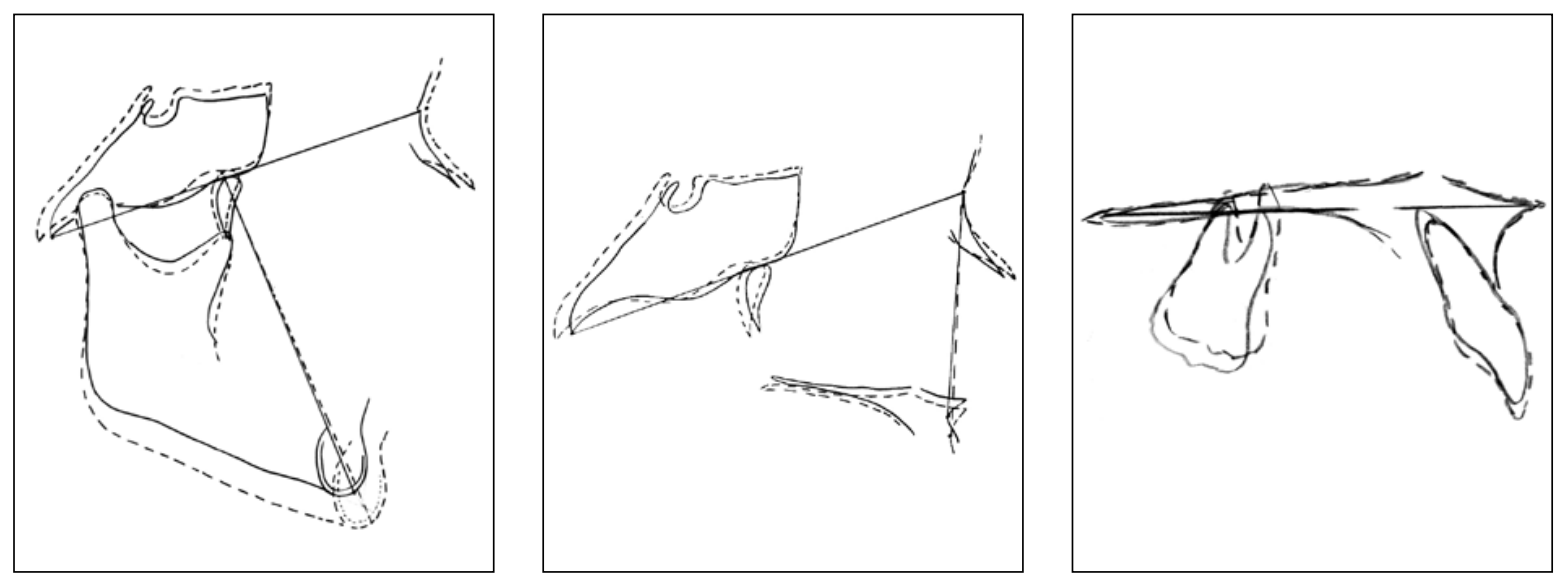

FIGURA 13 - Sobreposição cefalométrica na base do crânio, centrado nos pontos CC e N, para mostrar comportamento mandibular e maxilar. A sobreposição maxila isolada mostra o comportamento do arco dentário superior. 

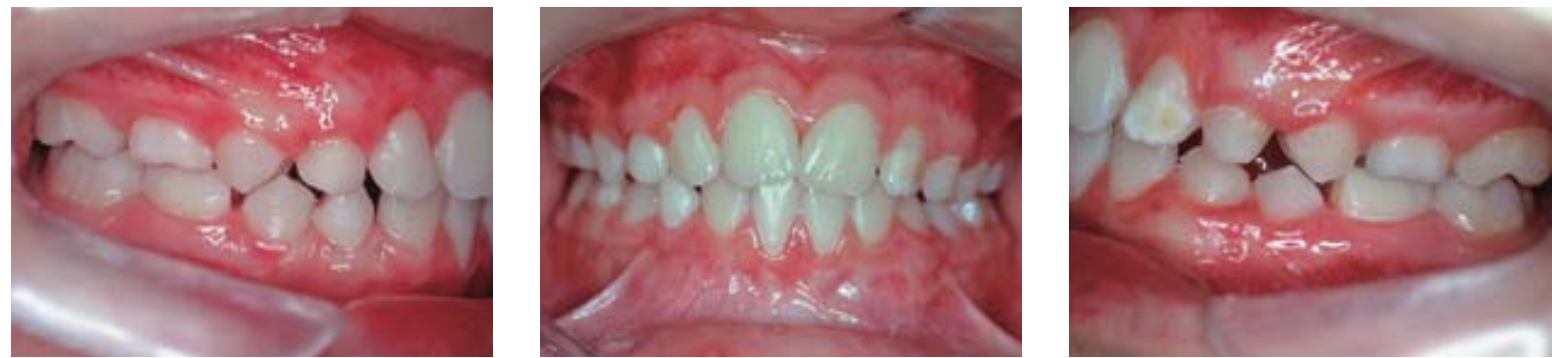

FIGURA 14 - Acompanhamento pós-tratamento, com o paciente no segundo período transitório da dentadura mista.
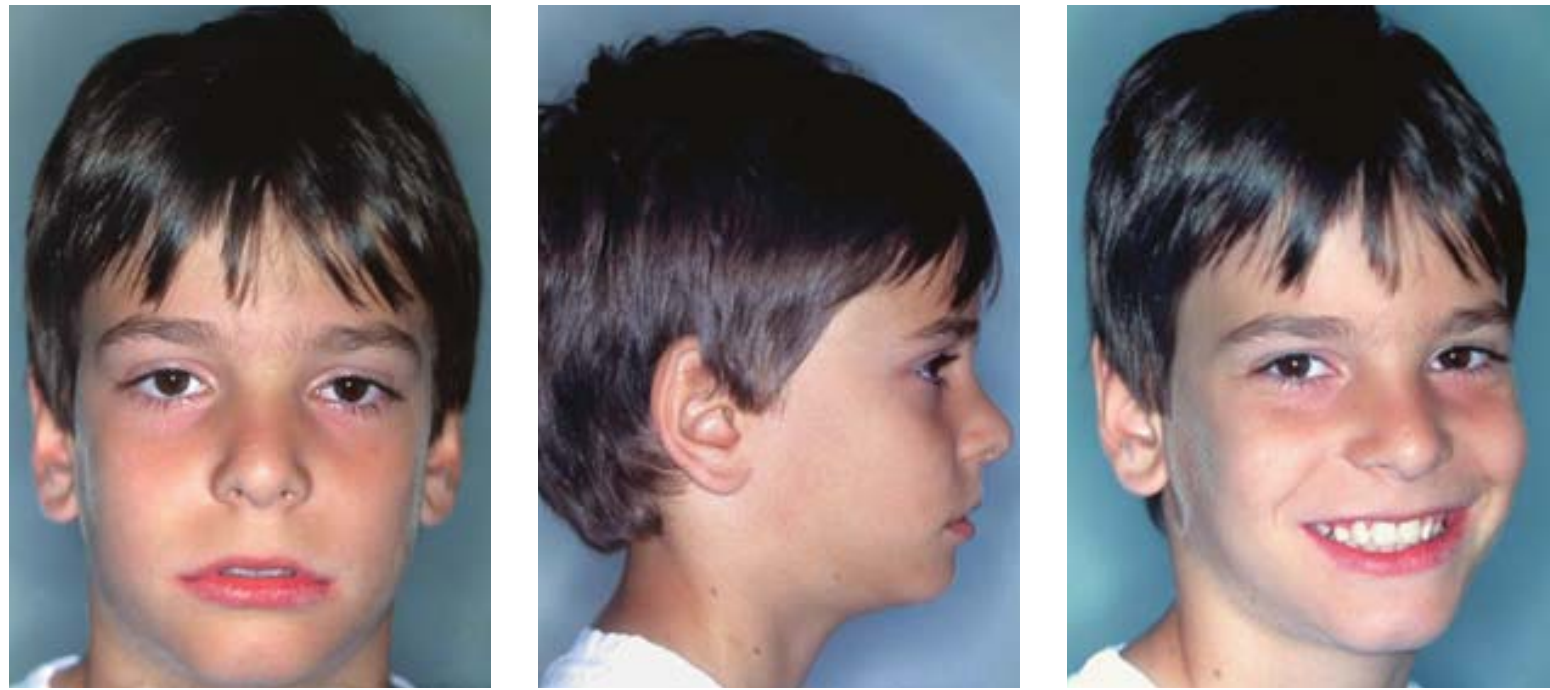

FIGURA 15 - Padrão Classe I, depois de corrigida a deficiência mandibular.
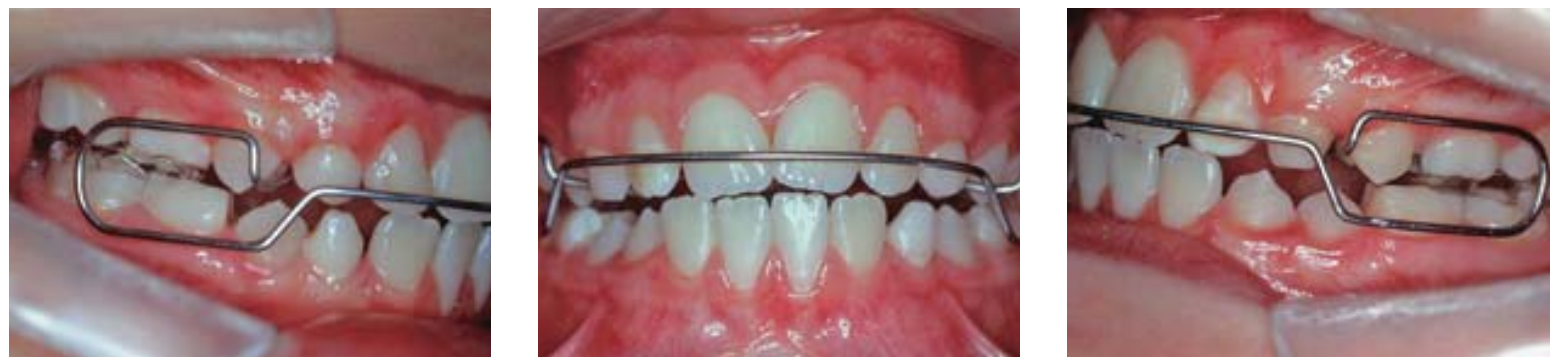

FIGURA 16 - A contenção obrigatória é conseguida com o aparelho ortopédico funcional removível: o Bionator.

\section{AVANÇO CONTÍNUO DA MANDÍBULA: MECANISMO TELESCÓPICO HERBST}

Pode-se considerar o aparelho Herbst uma espécie de precursor da ortopedia dentofacial, uma vez que precedeu o conceito da ortopedia funcional dos maxilares em remodelar as bases apicais, nos primórdios de 1900, libertando-nos do predomínio absoluto dos aparelhos removíveis, sempre sujeitos à cooperação do paciente. Além de definir os protocolos de tratamento ortopédico para a Classe II, o presente artigo descreve a aplicação do aparelho Herbst nas dentaduras mista e perma- 

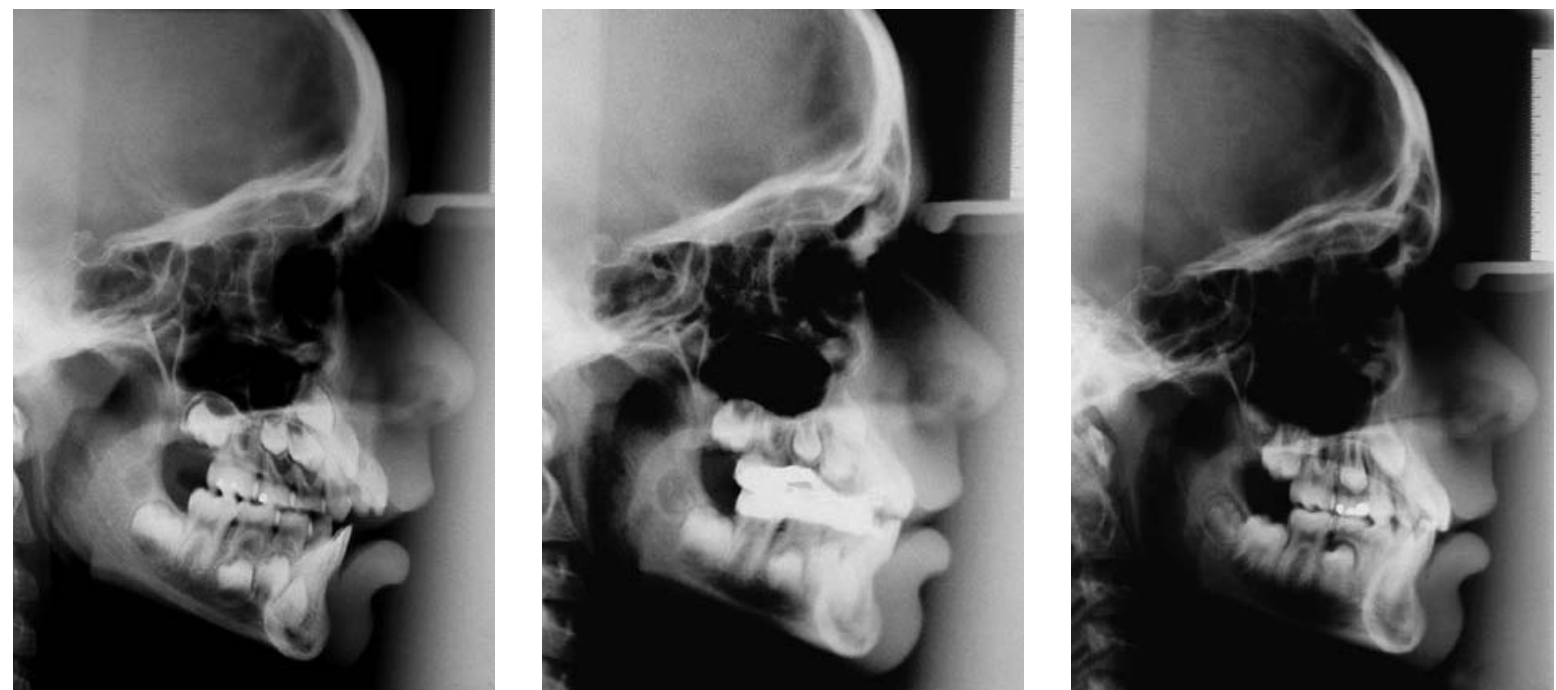

FIGURA 17 - Telerradiografias seriadas em três estágios: pré-tratamento, imediatamente após a instalação do mecanismo telescópico e no acompanhamento póstratamento.
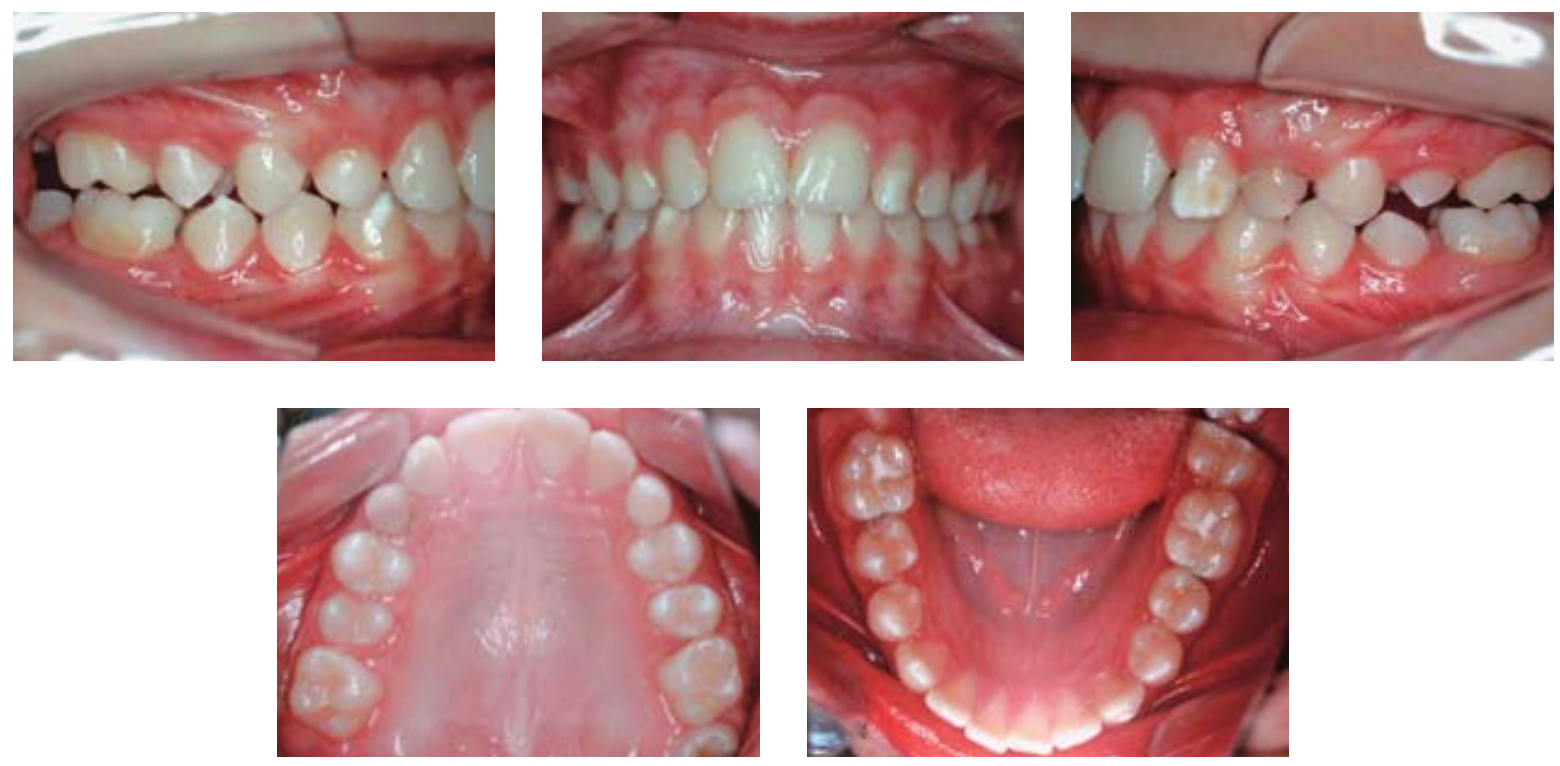

FIGURA 18 - Dentadura permanente. Oclusão normal tratada.

nente, obedecendo a um protocolo de tratamento precoce e tardio, respectivamente, complementando o artigo redigido previamente sobre a ancoragem do aparelho Herbst para a dentadura mista, no protocolo de tratamento precoce ${ }^{35}$.

A indiscutível superioridade do aparelho Herbst em relação aos aparelhos removiveis da
Ortopedia Funcional dos Maxilares reside no fato de ser fixo e, conseqüentemente, desencadear o avanço contínuo da mandíbula. Por isto, nenhum outro dispositivo dito ortopédico supera o aparelho Herbst no que se refere a tirar da mandíbula seu potencial máximo de crescimento induzido. As imagens da ATM, quer por ressonância 

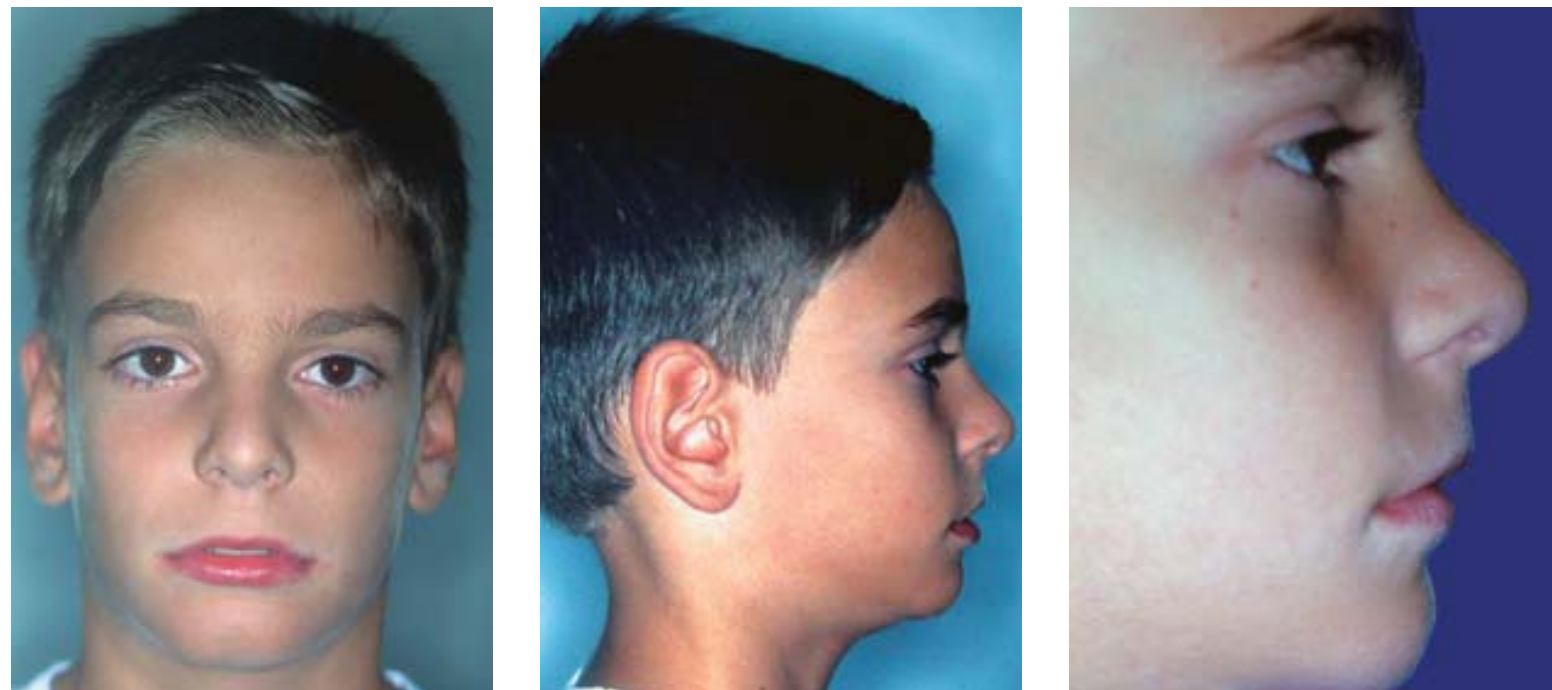

FIGURA 19 - Padrão I, no estágio de dentadura permanente (início da adolescência).
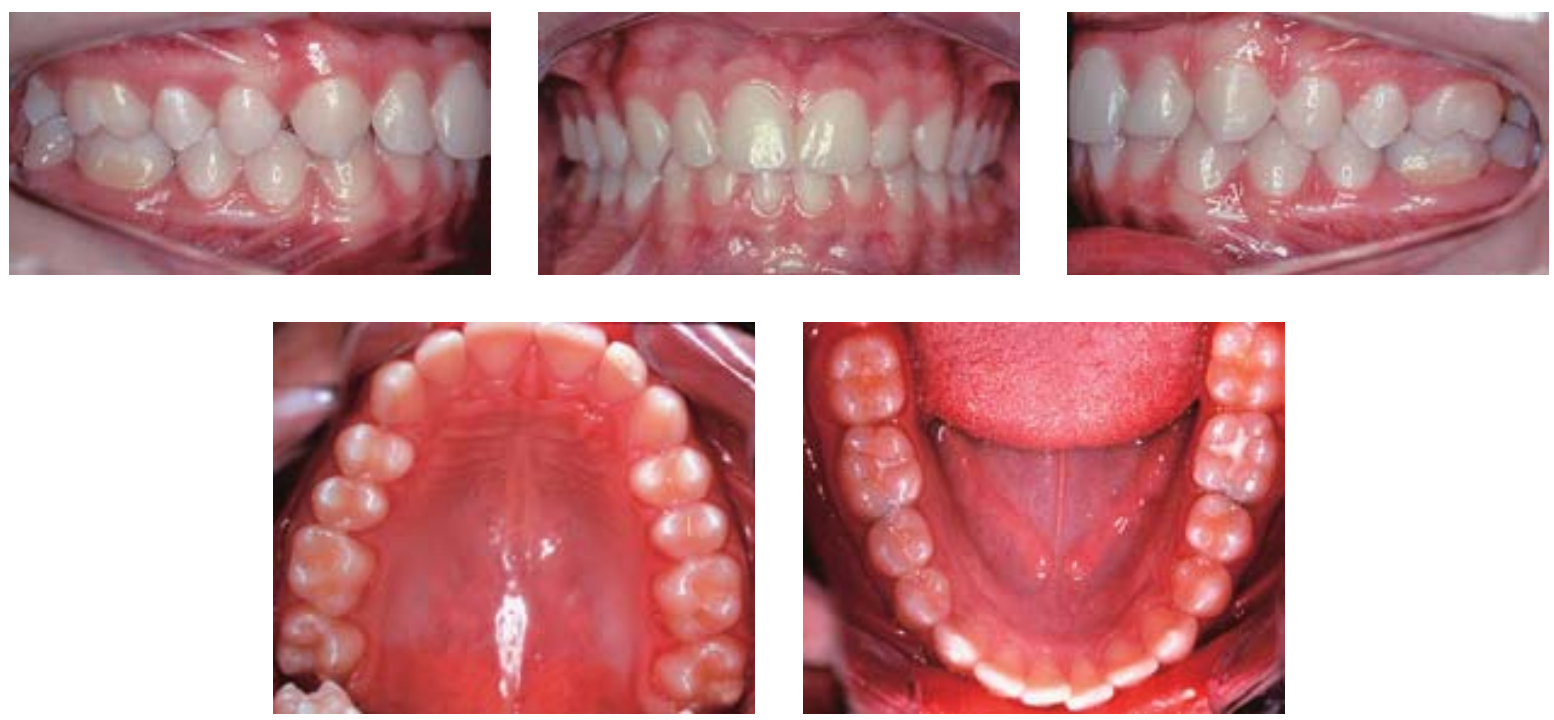

FIGURA 20 - Estágio de dentadura permanente. Na maturidade oclusal a oclusão exibe características de normalidade. Nesta fase, final da adolescência, o Bionator é suspenso e o controle do crescimento deve ser realizado anualmente até o término do crescimento. Em casos de instabilidade, observado pelo exame da oclusão, o Bionator pode ser reinstalado e monitorado até o término do crescimento.

eletromagnética, radiografias convencionais ou histologia, dão demonstração cabal do potencial de remodelação da ATM frente ao deslocamento contínuo do côndilo em direção à eminência articular. As pesquisas justificam o reposicionamento do côndilo dentro da fossa articular pelo crescimento condilar e pela remodelação da fossa articular ${ }^{42,43}$.
Isso não parece ser pura contaminação pelo entusiasmo que o aparelho fixo tem despertado em países que tradicionalmente cultivam aparelhos ortopédicos funcionais removiveis. Artigo recente em periódico nacional resume a literatura pertinente ao comportamento da ATM frente ao uso dos aparelhos ortopédicos ${ }^{36}$. 

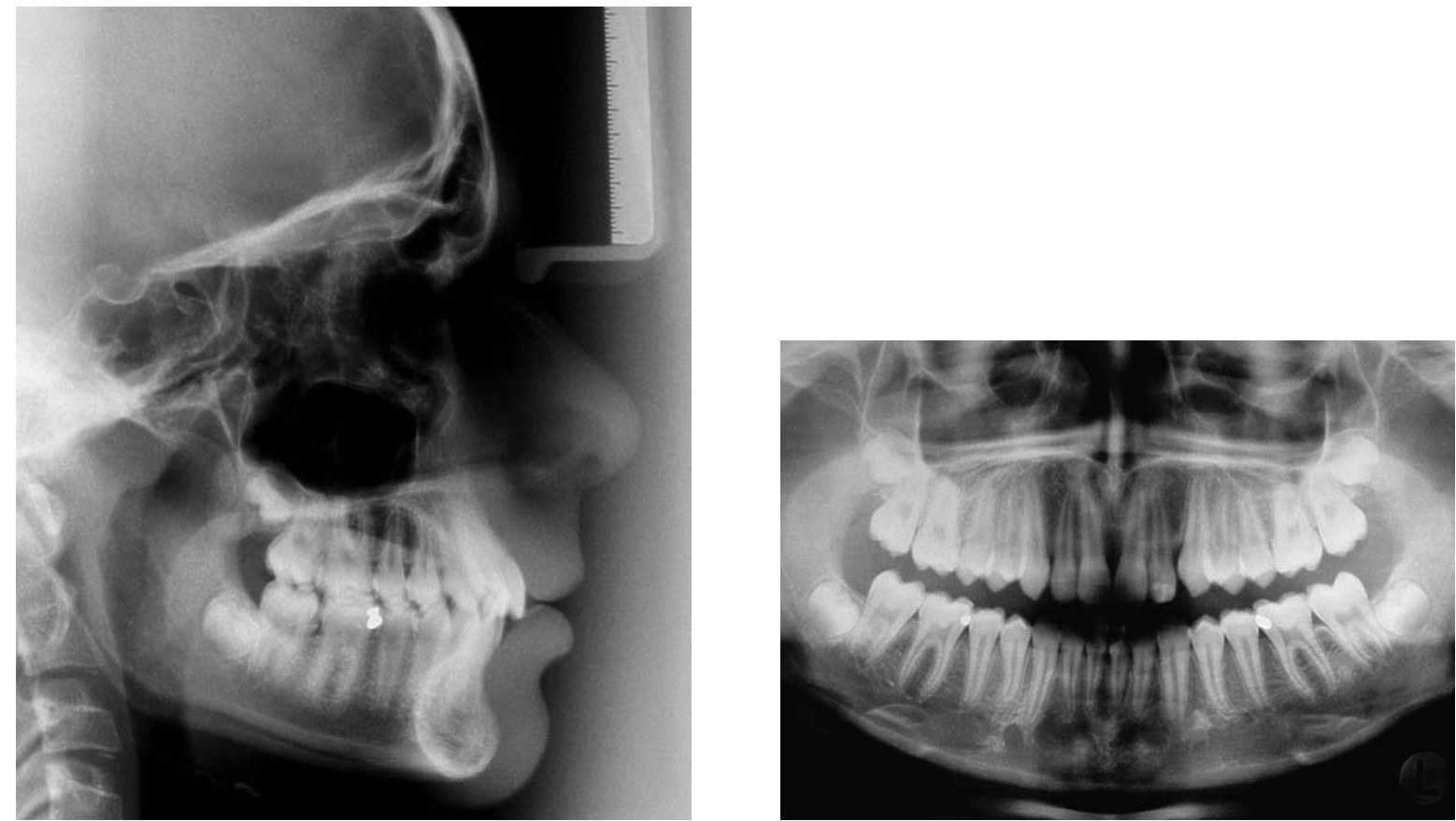

FIGURA 21 - Radiografias de controle no estágio de dentadura permanente e final da adolescência. Pela imagem da telerradiografia observa-se a estabilidade da correção ortopédica três anos após o uso do aparelho Herbst.
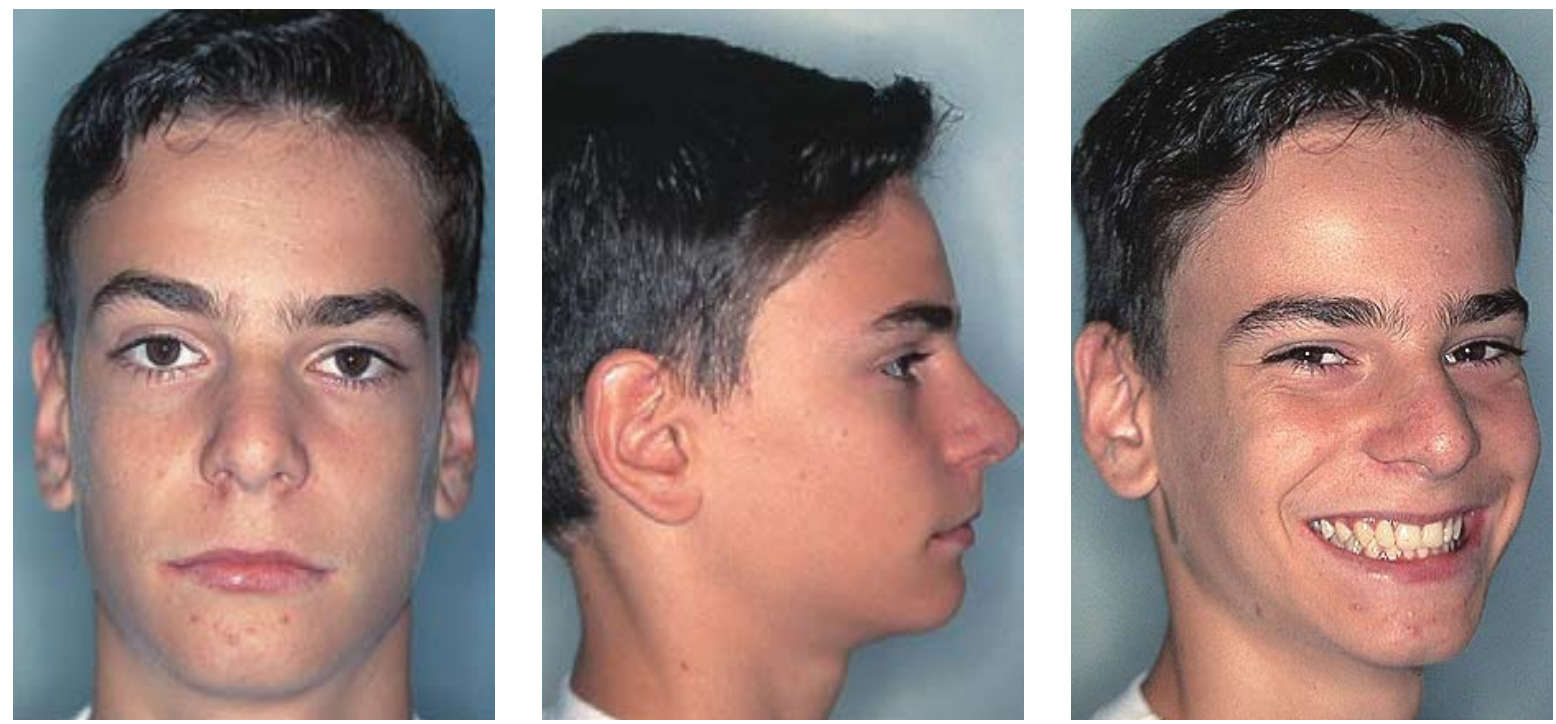

FIGURA 22 - Padrão I, no estágio inicial da dentadura permanente e no final da adolescência.

O avanço contínuo da mandíbula promove adaptação da função muscular dentro de um período relativamente curto, com aumento imediato da atividade eletromiográfica do músculo pteri- góideo lateral, seguido de redução gradual para os níveis de atividade pré-tratamento. Esse ciclo de atividade muscular ocorre dentro de 4 a 6 meses em humanos, de acordo com o único trabalho 
eletromiográfico em humanos ${ }^{10}$, e dentro de 8 a 12 semanas em macacos ${ }^{20}$. Essa adaptação muscular precede as alterações morfológicas remodelativas esperadas no côndilo e na fossa articular.

No que se refere aos efeitos ortopédicos, os conceitos correntes admitem, além da remodelação da ATM, aumento no comprimento mandibular e redução no comprimento maxilar ${ }^{29,31}$. O fato é que, como conseqüência do avanço contínuo da mandíbula, o aparelho Herbst aponta melhora oclusal, porém de impacto facial imprevisivel e, muito provavelmente, determinado pelo padrão de crescimento mandibular.

Assim como os aparelhos de avanço mandi- bular intermitente ${ }^{1,18,21,22}$, além de potencializar o crescimento mandibular, o aparelho de Herbst induz as nem sempre bem-vindas alterações ortodônticas, que podem alcançar mais de $50 \%$ do efeito total do aparelho ${ }^{38}$. As alterações ortodônticas podem ser consideradas "perda de ancoragem" e incluem: distalização e intrusão dos molares superiores ${ }^{23,32,29}$, verticalização dos incisivos superiores, vestibularização dos incisivos inferiores e extrusão e mesialização dos molares inferiores ${ }^{34}$. Pancherz ${ }^{29}$ menciona que mais de $40 \%$ da correção obtida com o aparelho Herbst pode ser atribuída ao reposicionamento posterior dos dentes posteriores superiores.

\title{
The Herbst appliance: early and late treatment protocol
}

\begin{abstract}
The question as to what extent mandibular growth may be influenced by orthopedic appliances remains unanswered. However, it seems reasonable to believe that the use of continuous forces potentialize the anterior displacement of the mandible. The current paper describes the early and late protocols of treatment of the mandibular deficiency with the Herbst appliance.
\end{abstract}

\section{REFERÊNCIAS}

1. ALMEIDA, M.R.; HENRIQUES, J. F. C.; FREITAS, M. R. PINZAN, A. Avaliação cefalométrica comparativa da interceptação da má oclusão de Classe II, 1a. divisão utilizando os aparelhos de Frankel e Bionator de Balters. R Dental Press Ortodon Ortop Facial, Maringá, v. 6, n. 6, p.11-27, nov./dez. 2001.

2. AMORIC, M. Thermoformed Herbst appliance. J Clin Orthod Boulder, v. 29, no. 3, p.173, Mar. 1995.

3. BREMEN, J V.PANCHERZ, $\mathrm{H}$. Efficiency of early and late Class II Division 1 treatment. Am J Orthod Dentofacial Orthop St. Louis, v. 121, no. 1, p. 31-37, Jan. 2002.

4. COELHO FILHO, C. M. Emprego clínico do aparelho para projeção da mandíbula. R Dental Press Ortodon Ortop Facial Maringá, v. 3, n. 5, p. 69-130, set./out. 1998.
5. DE VINCENZO, J. P. Changes in mandibular length before, during and after successful orthopedic correction of class II malocclusions, using a functional appliance. Am J Orthod Dentofacial Orthop, St. Louis, v. 99, no. 3, p. 241-257, Mar. 1991.

6. DISCHINGER, T. G. Edgewise bioprogressive Herbst appliance. J Clin Orthod, Boulder, v. 23, no. 9, p. 608-617, Sept. 1989.

7. FIRESTONE, A.; HÄSLER, R. U.; INGERVALL, B. Treatment results in dental school orthodontic patients in 1983 and 1993 Angle Orthod, Appleton, v. 69, no. 1, p.19-26, Feb. 1999.

8. GOODMAN, P.; MCKENNA, P. Modified Herbst appliance for the mixed dentition. J Clin Orthod, Boulder, v. 19, no.11, p. 811-814, Nov. 1985. 
9. HAEGGLUND, P. SEGERDAL, S. The Sweedish style integrated Herbst appliance. J Clin Orthod, Boulder, v. 31, no. 6, p. 378390, June 1997.

10. HIYAMA, S. et al. Neuromuscular and skeletal adaptations following mandibular forward positioning induced by the Herbst appliance. Angle Orthod, Appleton, v. 70, no. 6, p. 442-453, 2000

11. HOWE, R. P. The acrylic splint Herbst: problem solving. J Clin Orthod, Boulder, v.18, no. 7, p. 497-501, July 1984.

12. HOWE, R. P. The bonded Herbst appliance. J Clin Orthod Boulder, v.16, no.10, p. 663-667, Oct. 1982.

13. HOWE, R. P. Updating the bonded Herbst appliance. J Clin Orthod, Boulder, v. 17, no. 2, p.122-124, Feb. 1983.

14. HOWE, R. P.; McNAMARA Jr., J. A. Clinical management of the bonded Herbst appliance. J Clin Orthod, Boulder, v. 17, no. 7, p. 456-463, July 1983.

15. LANGFORD Jr., N. M. The Herbst appliance. J Clin Orthod Boulder, v.15, no. 8, p. 558-561, Aug. 1981

16. LANGFORD Jr., N. M. Updating fabrication of the Herbst appliance. J Clin Orthod, Boulder, v.16, no. 3, p. 173-174, Mar. 1982.

17. LIVIERATOS, F. A.; JOHNSTON, L. E. A comparison of one-stage and two-stage nonextraction alternatives in matched classe II samples. Am J Orthod Dentofacial Orthop, St. Louis, v.108, no. 2, p.118-131, Aug. 1995.

18. MARTINS, J. C. R. Avaliação cefalométrica comparativa dos resultados da interceptação da má oclusão de Classe II, divisão 1a de Angle, efetuados com o aparelho extrabucal ou com o bionator. 1997. 333 f. Tese (Livre-Docência) - Faculdade de Odontologia de Araraquara, Universidade Estadual Paulista, Araraquara, 1997.

19. McNAMARA Jr., J. A. Components of Class II malocclusion in children $8-10$ years of age. Angle Orthod, Appleton, v. 51, no. 3, p.177-202, July 1981

20. McNAMARA Jr., J. A. Neuromuscular and skeletal adaptations to altered function in the orofacial region. Am J Orthod, St. Louis, v. 64, no. 6, p. 578-606, Dec. 1973.

21. MCNAMARA Jr., J. A.; BOOKSTEIN, F. L.; SHAUGHNESSY, T.G. Skeletal and dental changes following functional regulator therapy on class II patients. Am J Orthod, St. Louis, v. 88, no. 2, p. 91-110, Aug. 1985

22. MCNAMARA Jr., J. A.; HOWE, R. P. Clinical management of the acrylic splint Herbst appliance. Am J Orthod Dentofacial Orthop, St. Louis, v. 94, no. 2, p.142-149, Aug. 1988.

23. McNAMARA Jr., J. A.; HOWE, R. P.; DISCHINGER, T. G. A comparison of the Herbst and the Frankel appliances in the treatment of class II malocclusion. Am J Orthod Dentofacial Orthop, St. Louis, v. 98, no. 2, p.134-144, Aug. 1990

24. NIELSEN, I. L. Facial growth during treatment with the function regulator appliance. Am J Orthod, St. Louis, v. 85, no. 5, p. 401 410, May 1984

25. O'BRIEN, K. D. et. al. The effectiveness of Class II Division treatment. Am J Orthod Dentofacial Orthop, St. Louis, v. 107, no.3, p. 329-334, Mar. 1995

26. PANGRAZIO-KULBERSH, V.; KACZYNSKI, R.; SHUNOCK, M Early treatment outcome assessed by the Peer Assessment Rating index. Am J Orthod Dentofacial Orthop, St. Louis, v.115, no. 5 , p. 544-550, May 1999
27. PANCHERZ, $H$. The effect of continuous bite jumping on the dentofacial complex: a follow-up study after Herbst appliance treatment of Class II maloclusions. Eur J Orthod, London, v. 3 , no. 1, p. 49-60, 1981.

28. PANCHERZ, H. The Herbst appliance its biological effects and clinical use. Am J Orthod, St. Louis, v. 87, no.1, p.1-20, Jan. 1985

29. PANCHERZ, $\mathrm{H}$. The mechanism of class II correction in Herbst appliance treatment: a cephalometric investigation. Am J Orthod, St. Louis, v. 82, no. 2, p.104-113, Aug. 1982.

30. PANCHERZ, H. The nature of Class II relapse after Herbst appliance treatment. A cephalometric long-term investigation. Am J Orthod Dentofacial Orthop, St. Louis, v. 100, no. 3, p. 220-233, Sept. 1991.

31. PANCHERZ, H. Treatment of Class II maloclusions by jumping the verte with the Herbst appliance: a cephalometric investigation. Am J Orthod, St. Louis, v. 76, no. 4, p. 423-441, Oct. 1979.

32. PANCHERZ, H.; ANEHUS-PANCHERZ, M. The headgear effect of the Herbst appliance: a cephalometric long-term study. Am J Orthod Dentofacial Orthop, St. Louis, v. 103, no. 6, p. 510-520, June 1993.

33. PANCHERZ, H.; HAAG, V. Dentofacial orthopedics in relation to somatic maturation. Am J Orthod, St. Louis, v. 88, no. 4, p. 273287, Oct. 1985

34. PANCHERZ, H.; HANSEN, K. Occlusal changes during and after Herbst treatment: a cephalometric investigation. Eur J Orthod London, v. 8, no. 4, p. 215-228, Nov. 1986.

35. SILVA FILHO, O. G. et al. Aparelho de Herbst: variações para uso na dentadura mista. R Dental Press Ortodon Ortop Facial, Maringá, v. 5, no. 5, p. 58-67, set./out. 2000.

36. SILVA FILHO, O. G. et al. O aparelho Herbst e as alterações adaptativas na ATM: revisão de literatura. J Bras Ortodon Ortop Facial, Curitiba, v.7, n. 41, p. 426-437, set./out. 2002.

37. TULLOCH, J. F. C.; PHILLIPS, C.; PROFITT, W. R. Benefit of early Class II treatment: progress report of two-phase randomized clinical trial. Am J Orthod Dentofacial Orthop, St. Louis, v. 113, no. 1, p. 62-72, Jan. 1998.

38. VALANT, J. R.; SINCLAIR, P. M. Treatment effects of Herbst appliance. Am J Orthod, St. Louis, v. 95, no. 2, p.138-147, Feb. 1989

39. WHITE, L. W. Current Herbst appliance therapy. J Clin Orthod, Boulder, v. 28, no. 5, p. 296-309, May 1994.

40. WIESLANDER, L. et al. Intensive treatment of severe Class II malocclusions with a headgear-Herbst appliance in the early dentition. Am J Orthod, St. Louis, v. 86, no. 1, p. 1-13, July 1984.

41. WINDMILLER, E. C. The acrylic-splint Herbst appliance: a cephalometric evaluation. Am J Orthod Dentofacial Orthop, St. Louis, v.104, no. 1, p. 73-84, July 1993.

42. WOODSIDE, D. G.; METAXAS, A.; ALTUNA, G. The influence of functional appliance therapy on glenoid fossa remodeling. Am J Orthod, St. Louis, v. 92, no. 3, p. 181-198, Sept. 1987.

43. WOODSIDE, D. G. et al. Primate experiments in malocclusion and bone induction. Am J Orthod, St. Louis, v. 83, no. 6 , p. 460-468, June 1983.

44. ZREIK, T. A fixed - removable Herbst appliance. J Clin Orthod, Boulder, v. 28, no. 4, p. 246-248, Apr. 1994.
Endereço para correspondência

Omar Gabriel da Silva Filho

Setor de Ortodontia do HRAC/USP

Rua Silvio Marchione, 3-20

CEP: $17043-900$

Bauru - SP

E-mail: ortoface@travelnet.com.br 